\title{
Patient Child Carrier of Ectodermal Dysplasia: Multidisciplinary Clinical Resolution in Dentistry
}

\author{
Juliana Larocca de Geus ${ }^{1,2 *}$, Karla Aguiar Cabral Cunha ${ }^{1}$, Gustavo Salem Ribeiro ${ }^{3}$, Yasmine \\ Mendes Pupo ${ }^{4}$, Gislaine Denise Czlusniak ${ }^{3}$
}

${ }^{1}$ Paulo Picanço School of Dentistry, Fortaleza, CE, Brazil, ${ }^{2}$ Guairacá Faculty, Guarapuava, PR, Brazil, ${ }^{3}$ State University of Ponta Grossa, PR, Brazil, ${ }^{4}$ Federal University of Paraná, PR, Brazil

\begin{abstract}
The aim of this case report was to rehabilitate the child patient bearer of Ectodermal Dysplasia (ED), using all available therapies in dentistry. This is a male patient, age 8 , leucoderma, which sought dental care, followed by his mother, went to the pediatric dentistry clinic at the State University of Ponta Grossa, Paraná, Brazil. We had to make anamnesis and clinical examination, where we noted the unusual anatomy and absence of some dental elements and dystrophic nails for scarce. We requested all documentation required to plan clinical treatment and procedures, involving pediatric dentistry, orthodontics, and surgery. Besides the oral rehabilitation, we observed an improvement in the self-esteem of the patient, who must be followed for future clinical approaches that can be applied according to the craniofacial growth.
\end{abstract}

Key Words: Ectodermal dysplasia, Child, Pediatric dentistry

\section{Introduction}

The term Ectodermal Dysplasia (ED) refers to a heritable change in the ectoderm, which is characterized by defective development during embryogenesis in one or more tissues [1-3]. The syndrome is considered a change of sex-linked recessive trait, although some forms of abnormality can be transmitted as autosomal dominant or recessive [1,4]. According to some authors, there are two types of ED: anhidrotic or hypohidrosis, called Christ-Siemens-Touraine Syndrome, and hidrotic, called Clouston syndrome [5,6].

The anhidrotic was first described by Thurnam in 1848 and later by Darwin [7]. It is usually transmitted by a recessive gene linked to chromosome $\mathrm{X}$. The gene is transmitted by women and the disorder usually manifests in men, characterized by the absence of some dental elements, dental abnormalities as conical teeth, lack of body hair, nail malformation and decreased sweating [7,8], and specific facial features [7]. The hypohidrosis is the most striking feature of this type of ED [9].

With regard to hidrotic ED is a rare autosomal dominant disorder characterized by dystrophic, alopecia nails, and palm hyperkeratosis $[6,10]$. The teeth and face abnormalities rarely present, and sweating [10], although Coskun and Bayraktaroglu [6] suggest the presence of sweat glands disorders. Ocular abnormalities include strabismus, premature cataracts, and conjunctivitis. Other abnormalities reported referring to the hearing reduction, polydactyly, and syndactyly. Delay may occur in mental development [10].

It is estimated that the frequency of the male population is 7:10,000 births [11]. These individuals' self-esteem is compromised and most often can change social life [12], especially if it is a child. Other consequences of this anomaly are loss of vertical dimension and the lip, resulting from improper development of the alveolar process lump, being caused by the absence of some dental elements [13].

Dental changes related to ED manifest early, can be easily detected in childhood. The diagnosis should occur as soon as possible so that treatment can contribute to physical, emotional and social development since patients with these conditions are usually withdrawn, shy and complexed [12,14]. Treatment of patients with the syndrome is complex and must have integral action and monitoring during the development of the child to the adult stage, in order to raise self-esteem and restore maximum functional and aesthetic $[12,15,16]$.

The aim of this case report was rehabilitating phonetic functions, aesthetic and masticatory in a child patient with ED, through multidisciplinary dental procedures.

\section{Case Report}

Patient RP, 8 years, male, white (Figure 1), with his mother, sought treatment at the clinic of pediatric dentistry at the State University of Ponta Grossa, Paraná, Brazil, due to the absence of some teeth (Figure 2).

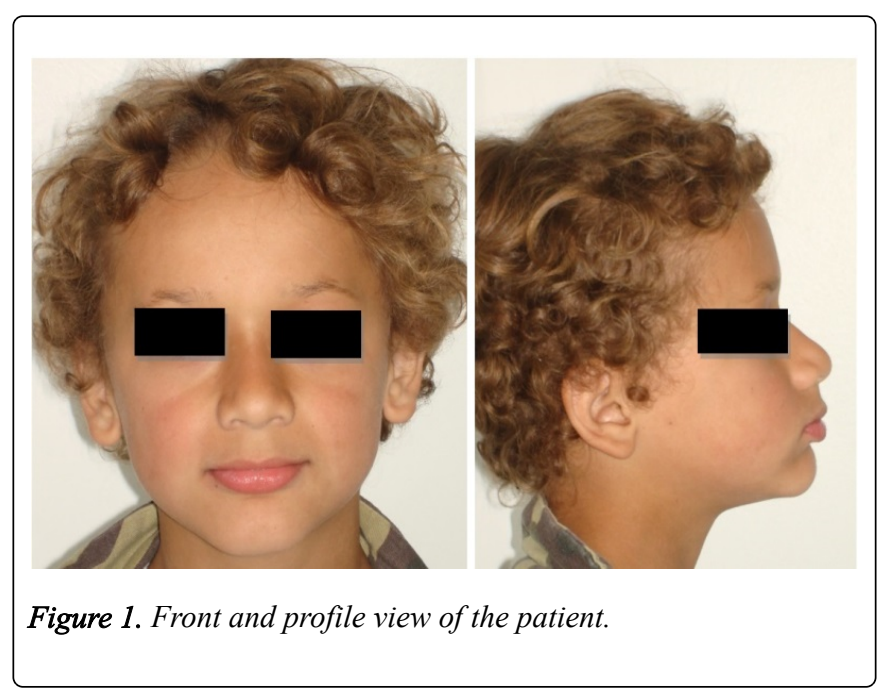

When performing the history and visual examination was observed unusual anatomy of the teeth, dystrophic nails and scarce pelage, characteristic of ectodermal dysplasia. No change in general health status has been reported. In the extraoral clinical examination, we observed light and thin hair, senile face and saddle nose. It was questioned whether there 
was anyone in the family with the same characteristics, reported that the maternal grandfather had the same genetic abnormality (Figure 3). For the initial planning of this clinical case, panoramic radiograph was performed.

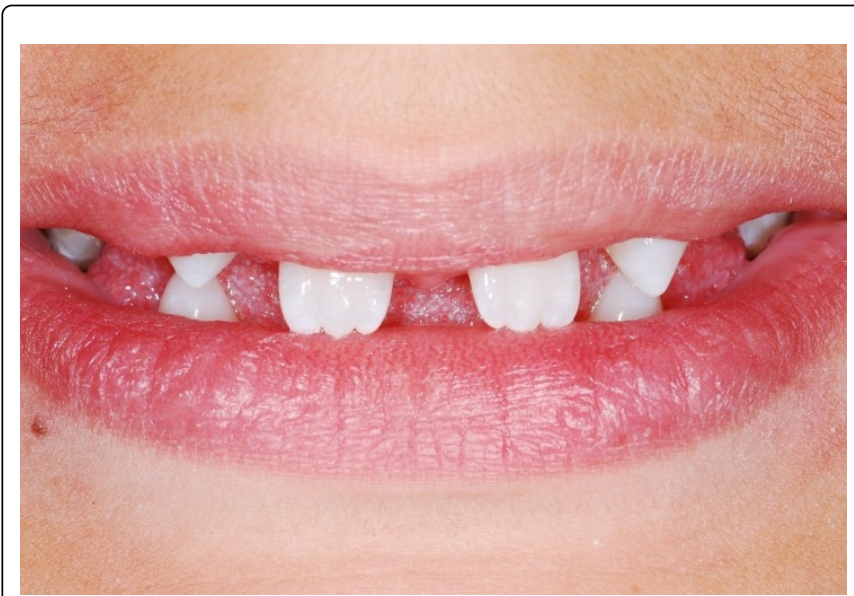

Figure 2. Initial smile.
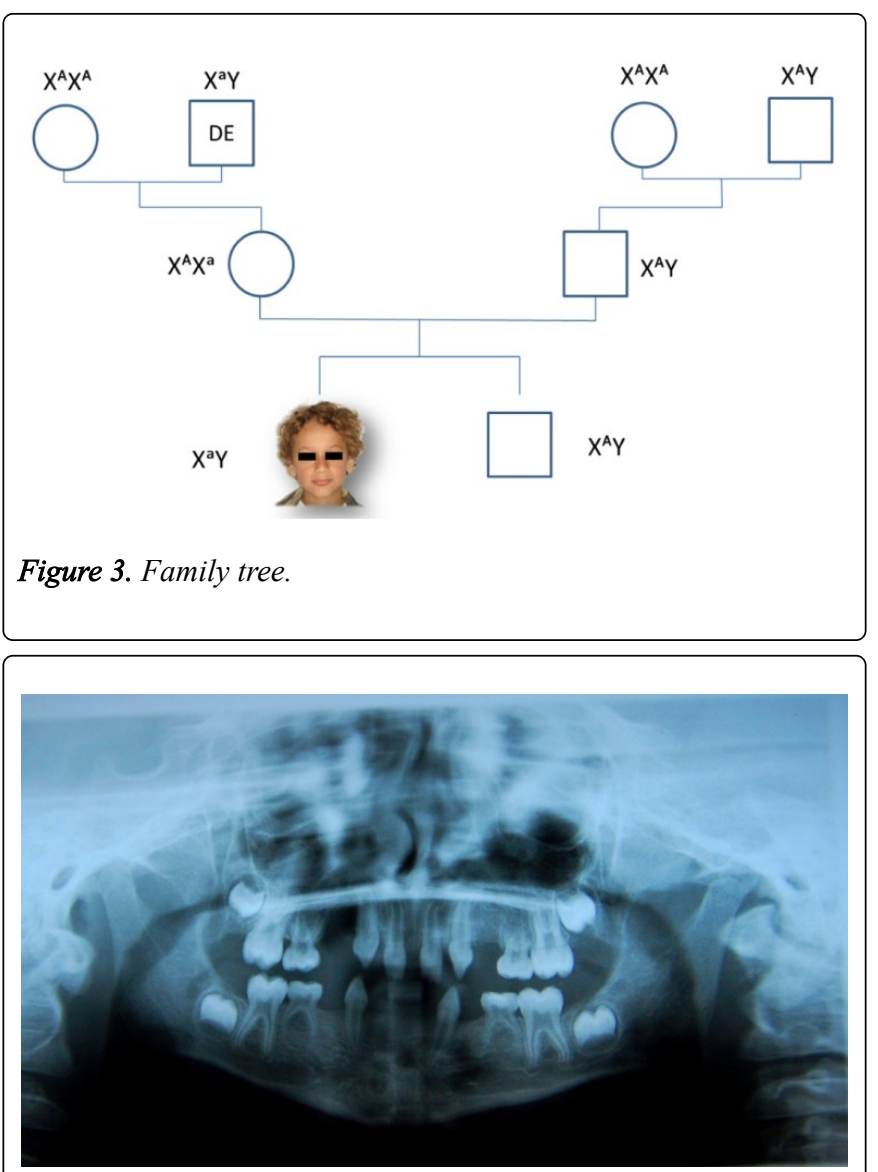

Figure 4. Panoramic radiography.

In the upper jaw, the patient had central incisors, deciduous canines, second molars, and permanent first molars. In the lower jaw were present the second deciduous molars and canines, beyond the first permanent molars. In radiography, the absence of various dental germs (Figure 4) was observed.

After the consent of the responsible, we started the treatment. In order to motivate the patient, oral hygiene orientation with disclosure of biofilm, sealants on permanent first molars and topical fluoride applications were made. Guidance on diet was also given.

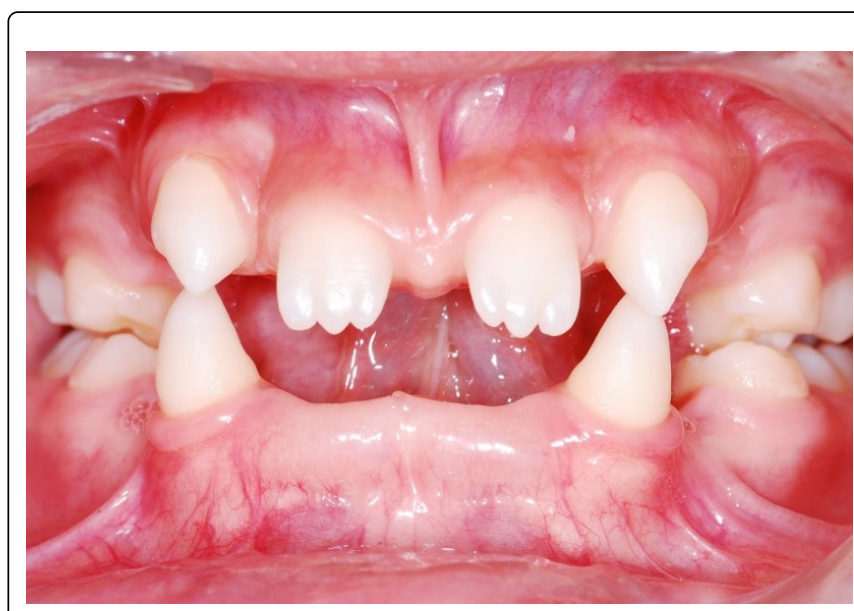

Figure 5. Presence of hypertrophic upper labial frenulum.

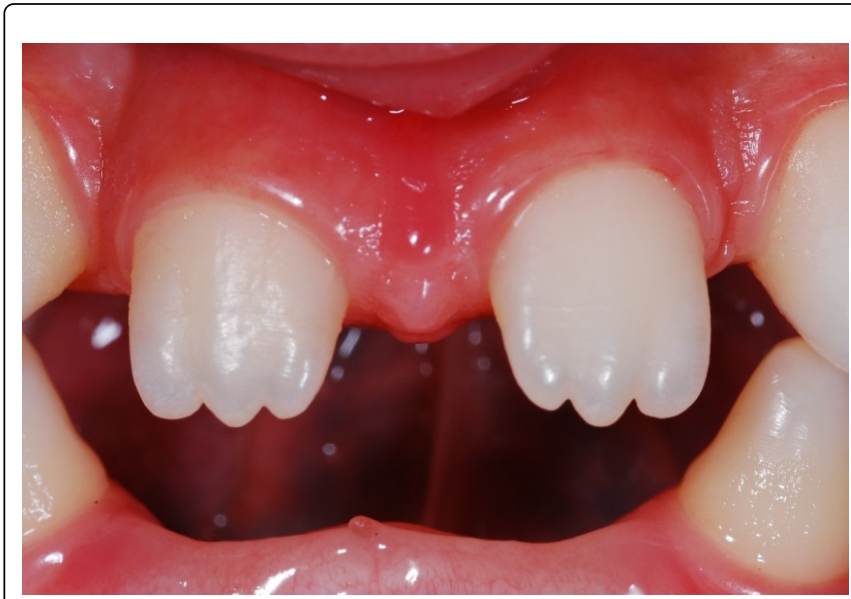

Figure 6. Results after two weeks of an upper labial frenectomy.

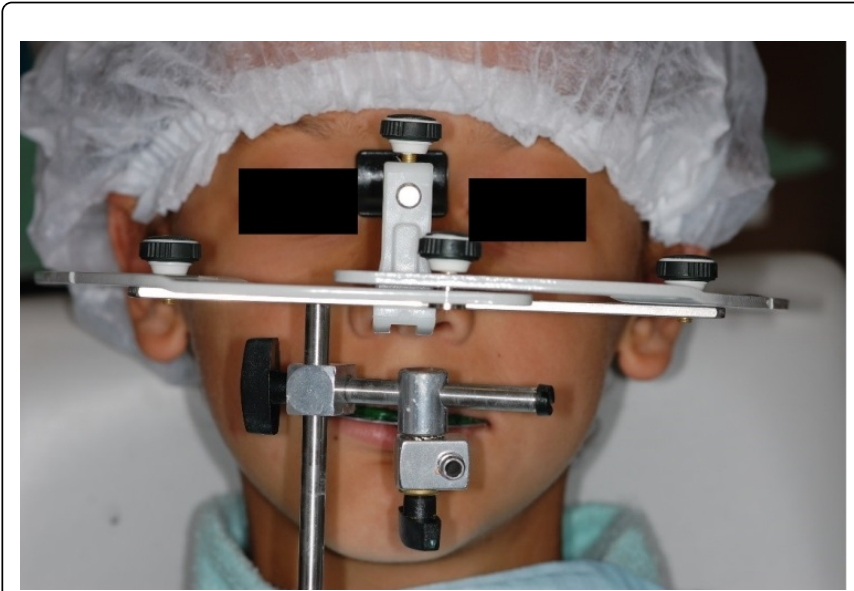

Figure 7. Taking the face-bow mounting of the models in the articulator

Afterward, the upper lip frenectomy was performed, since the brake presented hypertrophy, widening the spacing between the central incisors (Figures 5 and 6). 
For the correct planning of the rehabilitation, the patient was molded, and the necessary records were made for later assembly in an articulator (Figure 7).

After analysis in the articulator, we decided to perform flat direct tracks in composite resin in the second deciduous molars and selective wear on the premature contacts in lower canines, which contributed to the mandibular deviation, in order to uncross the bite. The final configuration of the tracks should be wide enough to block the return of the mandible to the deflected position and thick enough not to fracture when in function [17]. After obtaining the desired result the flat straight tracks were removed. Next, the application of sealants to the first permanent molars was performed.

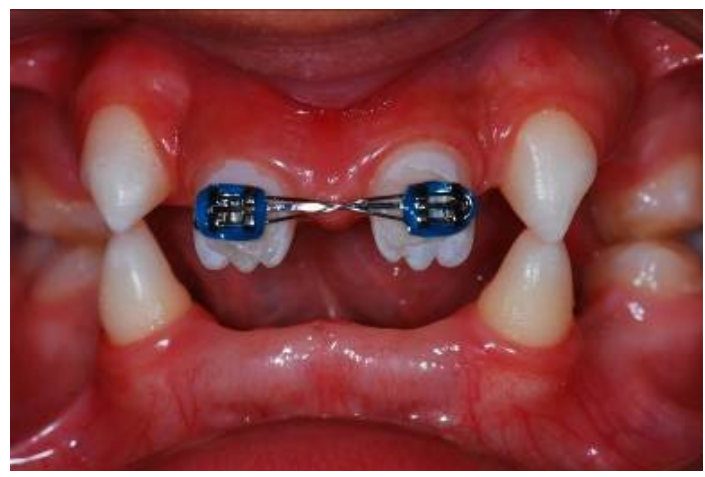

Figure 8. Beginning of orthodontic treatment.

After these procedures, the patient was referred to the radiological center for the preparation of orthodontic documentation, that is, study models, teleradiography and computerized cephalometric analysis. As a result, the Class I molar relationship, Class II canine relation was obtained, Point A convexity was defined as a straight profile, good positioning in the protrusion of the upper incisor as well as in the lower labial position, in the facial depth and the maxilla. As an expectation of a response to orthodontic treatment, the prognosis was classified as favorable.

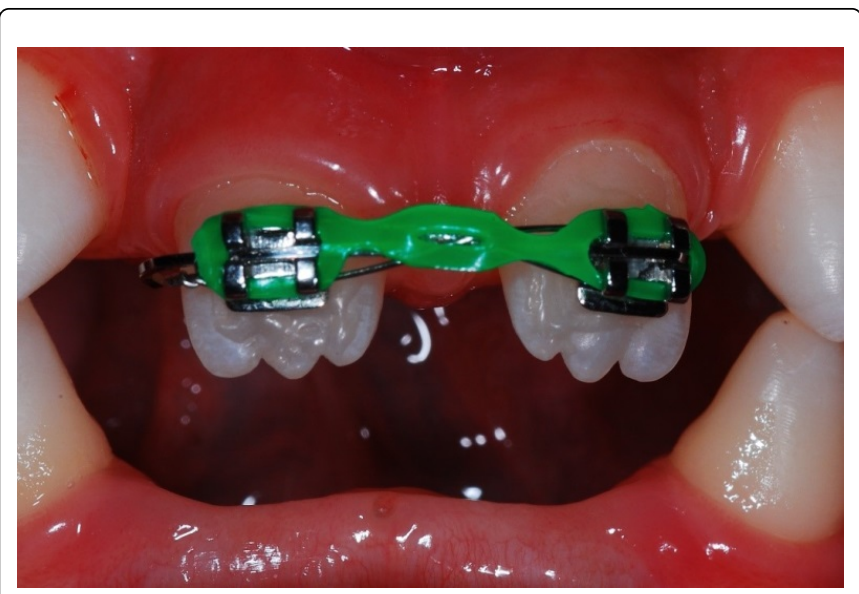

Figure 9. Closing of diastema in progress.

The orthodontic treatment lasted 6 months with the aim of closing the diastema between central incisors and distogiroversion of the superior canines, with consequent increase of the space for placement of the prosthesis with lateral incisors. In the inferior arch, a removable device was installed, where the Hawley bow was activated in the lower canines so that they were lingually (Figures 8-10).

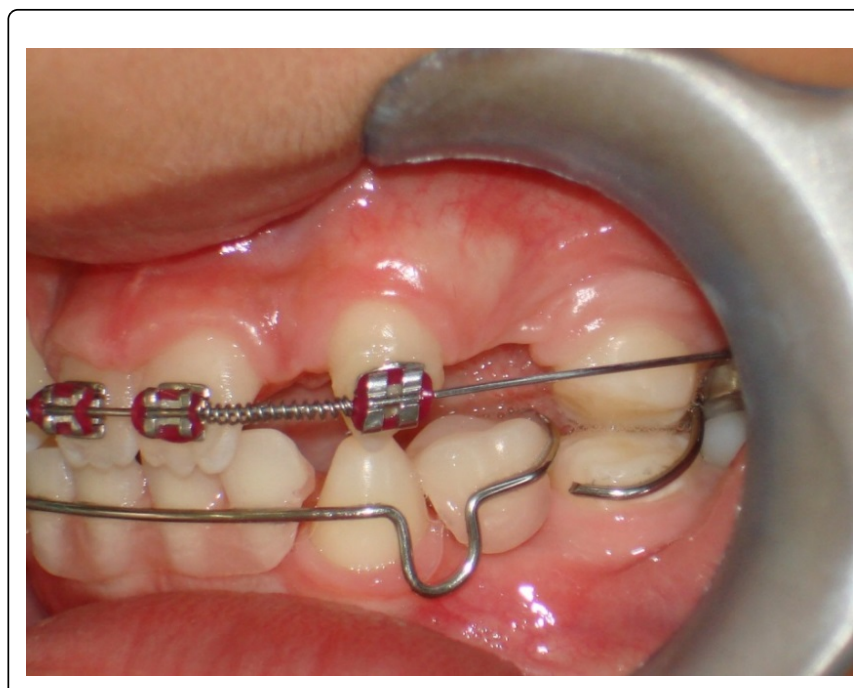

Figure 10. Springs to accomplish this giroversion of the upper canines and lower functional removable appliance.

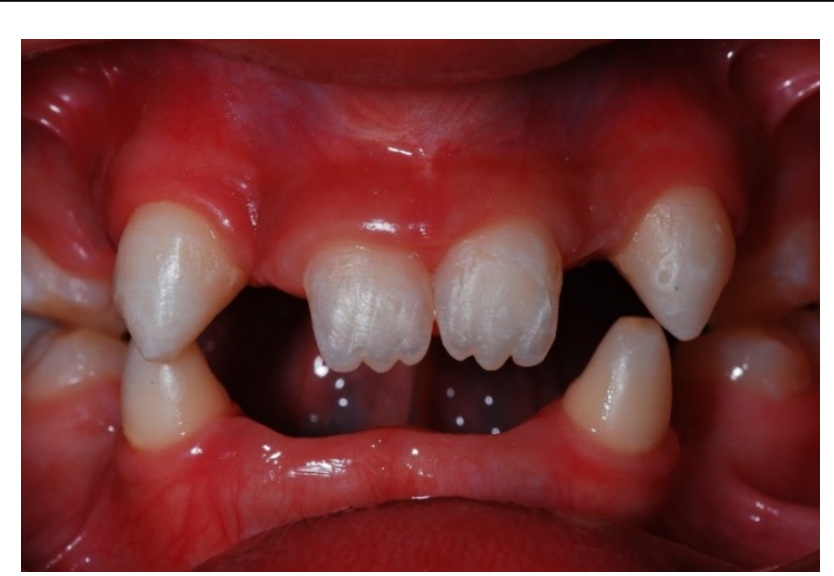

Figure 11. The result after orthodontic treatment.

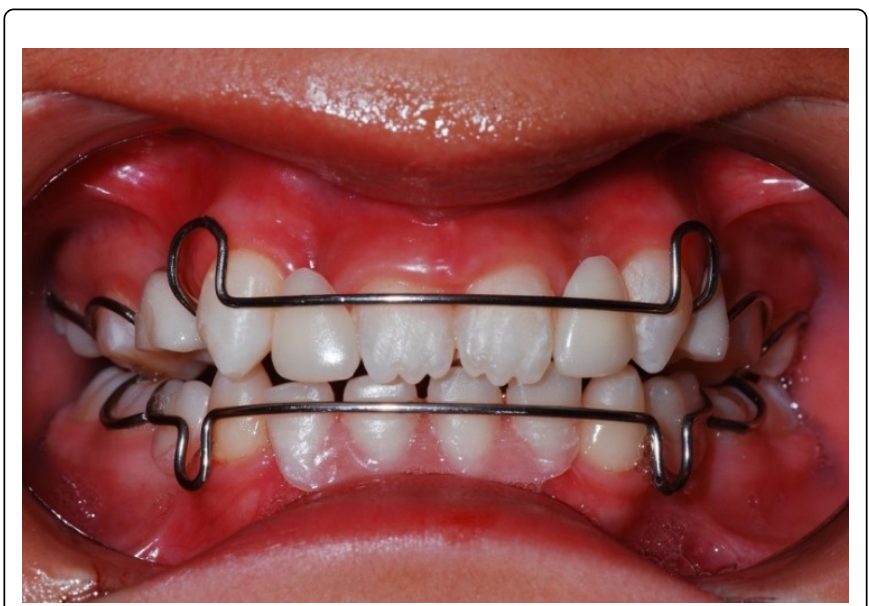

Figure 12. Final result.

After the orthodontic treatment was completed (Figure 11), functional maintainers were installed for the rehabilitation of the stomatognathic system (Figure 12). The purpose of this 
case report was to rehabilitate the patient as to the phonetic, masticatory function and esthetics, and improve their quality of life.

\section{Discussion}

The ED is a group of inherited anomalies that reveal abnormalities of ectodermal and derivatives thereof. In some situations, the signs may be less pronounced, but the dental anomalies can be striking [18], as observed in this case.

The diagnosis of this case was determined by history, clinical and radiographic examinations, the same way is done by other authors [14,19-21], where dental, facial, fine, light and scarce hairs were observed, featuring ED. Furthermore, there was a loss of vertical dimension and prominent lips. The patient reported no difficulty in sweating.

Histopathological examination of the skin is what provides the definitive diagnosis of ED. Currently, a prenatal exam by studying the DNA $[22,23]$ can be done. In the present case, these tests were not performed due to the high cost of both, but the clinical characteristics of the patient indicated that the patient had an anhydrosis ED.

The treatment depends on the extent of the clinical impairment, and the complexity is directly related to the patient's age and degree of involvement by the anomaly $[18,24,25]$.

In addition to the aesthetic and functional results, a treatment performed properly also helps in phonetics. As for the psychological aspect, you can considerably improve selfesteem and social interaction $[12,18,26]$. In this clinical case to obtain satisfactory results and because it is a child patient, that is, in the growth phase, we opted for removable functional appliances.

Follow up should be made until adulthood, where treatment with osseointegrated implants and prostheses [27,28] may provide a functional and aesthetic more harmonious, comparable to natural dentition.

In more complex cases the performance of the anomaly professionals like speech therapist and psychologist is required, and the age of the patient in such circumstances is directly related to the evolution, in other words, as soon as diagnosing, treating and associate with the assistance of other professionals, the better the results.

\section{Conclusion}

The dental protocol adopted in this clinical case of child patients with ED aimed to rehabilitate the stomatognathic system. Therefore, multidisciplinary clinical procedures involving pediatric dentistry, orthodontics and surgery were performed.

Besides oral rehabilitation was possible to observe an improvement in self-esteem of the child, which should be monitored so that future therapeutic approaches can be applied according to the craniofacial growth.

\section{References}

1. Argenziano G, Monsurrò MR, Pazienza R, Delfino M. A case of probable autosomal recessive ectodermal dysplasia with corkscrew hairs and mental retardation in a family with tuberous sclerosis. Journal of the American Academy of Dermatology. 1998; 38: $344-348$.

2. Ryan FS, Mason C, Harper JI. Ectodermal dysplasia-an unusual dental presentation. Journal of Clinical Pediatric Dentistry. 2005; 30: 55-57.

3. García-Martín P, Hernández-Martín A, Torrelo A. Ectodermal dysplasias: a clinical and molecular review. Actas DermoSifiliográficas. 2013; 104: 451-470.

4. Boj JR, Duran von Arx J, Cortada M, Jimenez A, Golobart J. Dentures for a 3-yr-old child with ectodermal dysplasia: Case report. American Journal of Dentistry. 1993; 6: 165-167.

5. Bakri H, Rapp R, Hadeed G. Clinical management of ectodermal dysplasia. Journal of Clinical Pediatric Dentistry. 1995; 19: $167-172$.

6. Coşkun Y, Bayraktaroğlu Z. Pathological case of the month. Ectodermal dysplasia. Archives of Pediatrics and Adolescent Medicine. 1997; 151: 741-742.

7. Ali G, Kumar M, Verma R, Khajuria V, Wadhwa MB. Anhidrotic ectodermal dysplasia (christ-seimens-touraine syndrome)case report with a review. Indian Journal of Medical Sciences. 2000; 54: 541-544.

8. Clauss F, Chassaing N, Smahi A, Vincent MC, Calvas P, et al. $\mathrm{X}$-linked and autosomal recessive hypohidrotic ectodermal dysplasia: genotypic-dental phenotypic findings. Clinical Genetics. 2010; 78: 257-266.

9. Rajendran R. Shafer's textbook of oral pathology. Philadelphia: Saunders 2009.

10. Tan E, Tay YK. What syndrome is this? Hidrotic ectodermal dysplasia (Clouston syndrome). Pediatric Dermatology. 2000; 17: 65-67.

11. Singh G, Kapoor A, Sharma V, Dhameja M. Ectodermal dysplasia: A case report. Indian Journal of Stomatology. 2012; 3: 187-189.

12. Saltnes SS, Jensen JL, Sæves R, Nordgarden H, Geirdal AØ. Associations between ectodermal dysplasia, psychological distress and quality of life in a group of adults with oligodontia. Acta Odontologica Scandinavica. 2017; 75: 564-572.

13. Dhamo B, Kuijpers MAR, Balk-Leurs I, Boxum C, Wolvius $\mathrm{EB}$, et al. Disturbances of dental development distinguish patients with oligodontia-ectodermal dysplasia from isolated oligodontia. Orthodontics and Craniofacial Research. 2018; 21: 48-56.

14. Chablani AA, Ram SM, Shetty O. Esthetic, functional and psychological management of ectodermal dysplasia using a full mouth rehabilitation approach. Journal of Contemporary Dentistry. 2013; 3: 92-97.

15. Suri S, Carmichael RP, Tompson BD. Simultaneous functional and fixed appliance therapy for growth modification and dental alignment prior to prosthetic habilitation in hypohidrotic ectodermal dysplasia: a clinical report. Journal of Prosthetic Dentistry. 2004; 92: 428-433.

16. Lo Muzio L, Bucci P, Carile F, Riccitiello F, Scotti C, et al. Prosthetic rehabilitation of a child affected from anhydrotic ectodermal dysplasia: a case report. Journal of Contemporary Dental Practice. 2005; 6: 120-126.

17. Chibinski ACR, Czlusniak GD, Melo MD. Pistas diretas planas: terapia ortopédica para correção de mordida cruzada funcional. Revista Clínica de Ortodontia Dental Press. 2005; 4: 64-72.

18. Nallanchakrava S. Oral rehabilitation of a patient with ectodermal dysplasia with prosthodontics treatment. Indian Journal of Dermatology. 2013; 58: 241. 
19. Anuroopa A, Abdulla J, Lovely M. Oral rehabilitation of a young patient with hypohidrotic ectodermal dysplasia: A clinical report. Contemporary Clinical Dentistry. 2012; 3: S33-S36.

20. Vasconcelos Carvalho M, Romero Souto de Sousa J, Paiva Correa de Melo F, Fonseca Faro T, Nunes Santos AC, et al. Hypohidrotic and hidrotic ectodermal dysplasia: a report of two cases. Dermatology Online Journal. 2013; 19: 18985.

21. Quintanilha LELP, Carneiro-Campos LE, Antunes LAA, Antunes LS, Fernandes CP, et al. Prosthetic rehabilitation in a pediatric patient with hypohidrotic ectodermal dysplasia: A case report. General Dentistry. 2017; 65: 72-76.

22. Rook A, Wilkinson DS, Ebling FJG. Textbook of dermatology. In: Harper JI, 6th ed. Great Britain: By Champion. 1998; 391-395.

23. Fitzpatrick TB, Irwin M. Dermatology in general medicine. In: Goldsmith LA, 5th ed. USA: Mc Graw-Hill, 1999; 805-806,

24. Della Valle D, Chevitarese AB, Maia LC, Farinhas JÁ. Alternative rehabilitation treatment for a patient with ectodermal dysplasia. Journal of Clinical Pediatric Dentistry. 2004; 28: 103-106.

25. Murdock S, Lee JY, Guckes A, Wright JT. A costs analysis of dental treatment for ectodermal dysplasia. Journal of the American Dental Association. 2005; 136: 1273-1276.

26. Wicomb GM, Stephen LX, Beighton P. Dental implications of Tooth-Nail dysplasia (Witkop syndrome): A report of an affected family and an approach to dental management. Journal of Clinical Pediatric Dentistry. 2004; 28: 107-112.

27. Kramer FJ, Baethge $\mathrm{C}$, Tschernitschek $\mathrm{H}$. Implants in children with ectodermal dysplasia: A case report and literature review. Clinical Oral Implants Research. 2007; 18: 140.

28. Knobloch LA, Larsen PE, Saponaro PC, L'Homme-Langlois E. Early implant placement for a patient with ectodermal dysplasia: Thirteen years of clinical care. Journal of Prosthetic Dentistry. 2018; 119: $702-709$. 